\section{FRI0330 $\quad$ BODY MASS INDEX AND DISEASE ACTIVITY IN CHRONIC INFLAMMATORY RHEUMATIC DISEASES: RESULTS OF THE CARDIOVASCULAR IN RHEUMATOLOGY (CARMA) PROJECT}

R. López-González ${ }^{1}$, J. A. Valero Jaimes², M. A. Martin-Martinez ${ }^{3}$, S. Castañeda ${ }^{4}$, C. García Gomez ${ }^{5}$, F. Sánchez-Alonso ${ }^{6}$, C. Gonzalez Juanatey $^{7}$, E. Revuelta-Evrad ${ }^{8}$, C. Perez-Garcia ${ }^{9}$, V. Torrente Segarra ${ }^{10}$, T. Pérez Sandoval ${ }^{11}$, J. Llorca ${ }^{12}$, M. A. González-Gay ${ }^{13}$ on behalf of CARMA Project Collaborative Group. ${ }^{1}$ Complejo Hospitalario de Zamora, Rhematology, Zamora, Spain; ${ }^{2}$ Hospital Universitario de Donosti, San Sebastián, Spain; ${ }^{3}$ Research Unit of Spanish Society of Rheumatology, Madrid, Spain; ${ }^{4}$ Hospital Universitario de la Princesa, Division of Rheumatology, Madrid, Spain; ${ }^{5}$ Consorci Sanitari de Terrassa, Division of Rheumatology, Terrassa, Barcelona, Spain; ${ }^{6}$ Research Unit of Spanish Society of Rheumatology, Madrid, Spain; ${ }^{7}$ Hospital Lucus Augusti, Division of Cardiology, Lugo, Spain; ${ }^{8}$ Hospital General Universitario de Ciudad Real, Division of Rheumatology, Ciudad Real, Spain; ${ }^{9}$ Hospital del Mar, Division of Rheumatology, Barcelona, Spain; ${ }^{10}$ Hospital Comarcal Alt Penedès Garraf, Division of Rheumatology, Barcelona, Spain; ${ }^{11}$ Complejo Asistencial Universitario de León, Division of Rheumatology, Leon, Spain; ${ }^{12}$ University of Cantabria and CIBER Epidemiología y Salud Pública, Santander, Spain; ${ }^{13}$ University of Cantabria. Hospital Universitario Marqués de Valdecilla, Division of Rheumatology, Santander, Spain

Objectives: Since obesity has been associated with higher inflammatory burden and worse response to therapy in patients with chronic inflammatory joint diseases (ClJDs), we aimed to confirm the potential association between body mass index (BMI) and disease activity in a large series of patients with CIJDs included in the Spanish CARdiovascular in rheuMAtology (CARMA) registry. Methods: Baseline data assessment of patients included from the CARMA project, a 10-year prospective study of patients with rheumatoid arthritis (RA), ankylosing spondylitis (AS) and psoriatic arthritis (PsA) attending outpatient rheumatology clinics from 67 Spanish hospitals. Obesity was defined when BMI $\left(\mathrm{kg} / \mathrm{m}^{2}\right)$ was $>30$ according to the WHO criteria. Scores used to evaluate disease activity were DAS28 in RA, BASDAI in AS, and modified DAS for PsA.

Results: Data from 2,234 patients (775 RA, 738 AS and 721 PsA) were assessed. The mean \pm SD BMI at the baseline visit were: $26.9 \pm 4.8$ in RA, $27.4 \pm 4.4$ in AS and $28.2 \pm 4.7$ in PsA. Multivariate analyses shown a positive association between $\mathrm{BMI}$ and disease activity in patients with RA ( $\beta$-coefficient: $0.029 ; 95 \% \mathrm{Cl}: 0.01-$ $0.05 ; p=0.007$ ) and in those with PsA ( $\beta$-coefficient: 0.036; 95\% Cl: 0.015-0.058; $\mathrm{p}=0.001$ ). By contrast, there was no significant association between BMI and disease activity in patients with AS ( $\beta$-coefficient: $0.001 ; 95 \% \mathrm{Cl}:-0.026-0.03$; $\mathrm{p}=0.926$ ).

In patients with RA, female gender ( $\beta$-coefficient: 0.546; $95 \% \mathrm{Cl}$ : 0.316-0.775; $p<0.001$ ) and rheumatoid factor status (seropositivity for RF) ( $\beta$-coefficient: $0.328 ; 95 \% \mathrm{Cl}: 0.106-0.549 ; p=0.004$ ) also showed a positive association with disease activity, while physical activity revealed a negative association with disease activity ( $\beta$-coefficient: -0.280 ; 95\% Cl: $-0.479-(-0.081) ; p=0.006)$.

Besides BMI, female gender ( $\beta$-coefficient: $0.720 ; 95 \%$ Cl: $0.524-0.916 ; p<0.001$ ), Psoriasis Area Severity Index ( $\beta$-coefficient: $0.038 ; 95 \%$ Cl: $0.012-0.066$; $\mathrm{p}=0.005$ ) and enthesitis ( $\beta$-coefficient: $0.256 ; 95 \% \mathrm{Cl}$ : 0.199-0.313; $\mathrm{p}<0.001$ ) were also positively associated with disease activity in PsA.

As observed in RA and PsA, female gender was also associated with disease activity patients with AS ( $\beta$-coefficient: 0.565; 95\% Cl: 0.299-0.832; $p<0.001$ ).

Conclusion: $\mathrm{BMI}$ is associated with disease activity in RA and PsA but not in AS. Since obesity is a potentially modifiable factor, disease activity was associated with female gender and RF status in RA and with Psoriasis Area Severity Index and enthesitis in PsA. Adequate control over body weight may improve the outcome of patients with CIJDs and, therefore, weight control should be included in the strategy of management of these patients.

Disclosure of Interests: Ruth López-González: None declared, Jesús Alejandro Valero Jaimes: None declared, Maria Auxiliadora Martin-Martinez: None declared, Santos Castañeda: None declared, Carmen García Gomez: None declared, Fernando Sánchez-Alonso: None declared, Carlos Gonzalez Juanatey: None declared, Eva Revuelta-Evrad: None declared, Carolina Perez-Garcia: None declared, Vicenç Torrente Segarra: None declared, Trinidad Pérez Sandoval: None declared, Javier Llorca: None declared, Miguel A González-Gay Grant/research support from: Pfizer, Abbvie, MSD, Speakers bureau: Pfizer, Abbvie, MSD DOI: 10.1136/annrheumdis-2020-eular.3591

\section{FRI0331 \\ COMPARISON OF THE THERAPEUTIC TRAJECTORIES OF PATIENTS WITH OLIGO AND POLYARTICULAR PSORIATIC ARTHRITIS. A REPORT FROM THE RHUMADATA $®$ CLINICAL DATABASE AND REGISTRY}

D. Choquette $^{1}$, L. Choquette Sauvageau ${ }^{1}$, L. Bessette ${ }^{2}$, I. Ferdinand ${ }^{1}$,

P. Haraoui ${ }^{1}$, F. Massicotte ${ }^{1}$, J. P. Pelletier ${ }^{1}$, J. P. Raynauld ${ }^{1}$, M. A. Rémillard ${ }^{1}$
D. Sauvageau ${ }^{1}$, É. Villeneuve ${ }^{1}$, L. Coupal ${ }^{1} .{ }^{1}$ Institut de Recherche en Rhumatologie de Montréal, Montréal, Canada; ${ }^{2}$ Centre de l'Ostéoporose et de Rhumatologie de Québec, Québec, Canada

Background: Psoriatic Arthritis (PsA) most frequently presents as a polyarthritis or (less often) as an oligoarthritis [1]. Most of the patients in the original description of Moll and Wight had an oligoarticular presentation [2]. However, other studies have not found the same distribution in all patient populations [3]. Treatment response over time across presentation types has not been explored thoroughly in recent medical literature.

Objectives: Using our proposed definition of oligo and polyarticular PsA status, based on the (rounded) mean of the first four available joint counts, we examine treatment sequences in each group.

Methods: Data from patients participating in the RHUMADATA ${ }^{\circ}$ clinical database and registry diagnosed with PsA were extracted on January $5^{\text {th }}, 2020$. Joint count classification (oligo vs. poly) was assessed from the average of the first four available $66 / 68$ joint counts. Patients were classified as having a polyarticular form of PsA if the (rounded) average, five or more of their joints were assessed as being swollen and/or tender. Subjects with four or less swollen or tender joints were classified as patients having oligoarticular PsA. Time spent treated with non-DMARDs, csDMARDs and bDMARDs, time to treatment (to csDMARDs and bDMARDs) and treatment selection were assessed from the entire PsA cohort. Continuous variables were tested using t-tests and binary variables using Fisher's exact test.

Results: The data from all patients diagnosed with PsA $(n=1029)$ was extracted from the RHUMADATA $\AA$ clinical database and registry. All but 151 (15\%) were classifiable, 470 (46\%) were classified as oligoarticular PsA patients and 408 (39\%) as polyarticular. Time from the first symptoms to the first clinic visit was $4.6 \pm 6.5$ years and $3.7 \pm 6.6$ ( $p$-value $=0.1311$ ) years for the patients classified as oligo and poly respectively. A total oh 951 patients were treated with a csDMARD (144 of those could not be classified as oligo or poly). For those, time from diagnosis to first csDMARD (prior to any bDMARD) treatment was $1.7 \pm 5.3$ (oligo) years and $2.0 \pm 7.0$ (poly) years ( $p$-value=0.4114). Methotrexate (MTX), hydroxychloroquine (HCQ) and leflunomide (LEF) were more frequently prescribed to polyarticular than oligoarticular PsA patients (MTX: $70 \%$ (poly) vs. $48 \%$ (oligo), p-value<.0001, HCQ: $41 \%$ vs. $25 \%$, p-value $<.0001$, LEF: $17 \%$ vs. $8 \%$, p-value $<.0001$, Sulfasalazine (SSZ): $17 \%$ vs. $19 \%$, p-value $=0.5232$, Other csDMARDs: $5 \%$ vs. $4.5 \%$, p-value=0.8688). A total of 648 patients were treated with a bDMARD (151 of those could not be classified as oligo or poly). For those time from first csDMARD Rx to first bDMARD treatment was $6.3 \pm 4.6$ (oligo) years and $7.0 \pm 4.7$ years $(p$-value $=0.0865)$. On average, over the entire treatment history, oligoarticular patients received $1.7 \pm 1.2$ biologic agents and polyarticular $2.0 \pm 1.4$, p-value $=0.0110$. bDMARDs were administered over $3.6 \pm 3.6$ years for oligo and $4.5 \pm 3.9$ years for poly, $p$-value $=0.2122$.

Conclusion: Polyarticular PsA patients appear to be more aggressively treated than oligoarticular patients during the csDMARDs period. Although durations on bDMARDs are statistically similar, polyarticular patients change biotreatment more frequently.

\section{References:}

[1] Gladman DD, Ritchlin C, et al. Clinical manifestations and diagnosis of psoriatic arthritis. Update 2019.

[3] Wright V, Moll JM. Psoriatic arthritis. Bull Rheum Dis 1971; 21:627.

[3] Gladman DD. Psoriatic arthritis. Baillieres Clin Rheumatol 1995; 9:319.

Disclosure of Interests: Denis Choquette Grant/research support from: Rhumadata is supported by grants from Pfizer, Amgen, Abbvie, Gylead, BMS, Novartis, Sandoz, eli Lilly,, Consultant of: Pfizer, Amgen, Abbvie, Gylead, BMS, Novartis, Sandoz, eli Lilly,, Speakers bureau: Pfizer, Amgen, Abbvie, Gylead, BMS, Novartis, Sandoz, eli Lilly, Loïc Choquette Sauvageau: None declared, Louis Bessette Grant/research support from: AbbVie, Amgen, Bristol-Myers Squibb, Celgene, Eli Lilly, Janssen, Merck, Novartis, Pfizer, Roche, Sanofi, UCB Pharma Consultant of: AbbVie, Amgen, Bristol-Myers Squibb, Celgene, Eli Lilly, Janssen, Merck, Novartis, Pfizer, Roche, Sanofi, UCB Pharma, Speakers bureau: AbbVie, Amgen, Bristol-Myers Squibb, Celgene, Eli Lilly, Janssen, Merck, Novartis, Pfizer, Sanofi, Isabelle Ferdinand Consultant of: Pfizer, Abbvie, Amgen, Novar tis, Speakers bureau: Pfizer, Amgen, Paul Haraoui Grant/research support from: AbbVie, Amgen, BMS, Janssen, Pfizer, Roche, and UCB, Consultant of: AbbVie, Amgen, BMS, Celgene, Eli Lilly, Janssen, Merck, Pfizer, Roche, and UCB Speakers bureau: Pfizer, Speakers bureau: Amgen, BMS, Janssen, Pfizer, and UCB, Frédéric Massicotte Consultant of: Abbvie, Janssen, Lilly, Pfizer, Speakers bureau: Janssen, Jean-Pierre Pelletier Shareholder of: ArthroLab Inc., Grant/ research support from: TRB Chemedica, Speakers bureau: TRB Chemedica and Mylan, Jean-Pierre Raynauld Consultant of: ArthroLab Inc., Marie-Anaïs Rémillard Consultant of: Abbvie, Amgen, Eli Lilly, Novartis, Pfizer, Sandoz, Paid instructor for: Abbvie, Amgen, Eli Lilly, Novartis, Pfizer, Sandoz, Speakers bureau: Abbvie, Amgen, Eli Lilly, Novartis, Pfizer, Sandoz, Diane Sauvageau: None declared, Édith Villeneuve Consultant of: Abbvie, Amgen, BMS, Celgene, Pfizer, Roche, Sanofi-Genzyme, 
UCB, Paid instructor for: Abbvie, Speakers bureau: AbbVie, BMS, Pfizer, Roche, Louis Coupal: None declared

DOI: 10.1136/annrheumdis-2020-eular.4339

\section{FRI0332 EVALUATION OF THE INDIVIDUAL COMPONENTS OF ACR50+PASI100 AND MDA AT WEEK 24 FROM THE SPIRIT-H2H TRIAL COMPARING THE EFFICACY AND SAFETY OF IXE VERSUS ADA IN PATIENTS WITH PSA NAÏVE TO BDMARDS}

L. C. Coates ${ }^{1}$, M. Nissen ${ }^{2}$, C. El Baou ${ }^{3}$, J. Zochling ${ }^{4}$, A. Marchesoni ${ }^{5}$, S. Liu Leage $^{6}$, E. Soriano ${ }^{7}$, V. F. Azevedo ${ }^{8}$, K. Machold ${ }^{9}$, C. Sapin ${ }^{6} .{ }^{1}$ Nuffield Department of Orthopaedics, Rheumatology and Musculoskeletal Sciences, Oxford, United Kingdom; ${ }^{2}$ University of Geneva, Rheumatology, Geneva, Switzerland; ${ }^{3}$ Eli Lilly Research \& Development, Windlesham, United Kingdom; ${ }^{4}$ Rheumatology Tasmania, Hobart, Australia; ${ }^{5}$ ASST Gaetano Pini-CTO Polo Isocrate, Milano, Italy; ${ }^{6}$ Eli Lilly and Company Corporate Center, Indianapolis, United States of America; ${ }^{7}$ Hospital Italiano de Buenos Aires, ABH, Argentina; ${ }^{8}$ Federal University of Parana, Curitiba, Brazil; ${ }^{9}$ Medical University of Vienna, Wien, Austria

Background: Psoriatic arthritis (PsA) is a chronic systemic disease with manifestations affecting musculoskeletal and extra-articular domains. Treatment and assessment of response are therefore major challenges in routine clinical practice. Minimal disease activity (MDA) is a multidimensional endpoint that can define a treatment target ${ }^{1}$. In SPIRIT-H2H ${ }^{2}$, a head-to-head clinical trial comparing the efficacy and safety of ixekizumab (IXE) versus) to adalimumab (ADA), the percentage of patients simultaneously achieving American College of Rheumatology 50 (ACR50) and Psoriasis Area and Severity Index 100 (PASI100), was the primary endpoint in order to reflect improvement in two domains of PsA.

Objectives: To evaluate how individual components of the simultaneous achievement of ACR50 and PASI100 compare with those of MDA at week 24.

Methods: Patients with active PsA (defined as those with a tender joint count $[T J C] \geq 3 / 68$, a swollen joint count [SJC] $\geq 3 / 66$ and a body surface area [BSA] of active plaque psoriasis $\geq 3 \%$ ) were randomised $1: 1$ to approved dosing (according to baseline psoriasis involvement) of IXE or ADA in SPIRIT-H2H, an open label, assessor-blinded study.

The proportion of patients meeting each criterion of the composite endpoints was calculated for the intent-to-treat ([ITT], $\mathrm{N}=566$ ) population and the population of MDA responders at Week $24(\mathrm{~N}=235)$. Missing individual responses were imputed with non-responder status. Spidergrams were generated using SAS 9.4. Results:

For both the overall ITT population and the MDA responders population, the use of $\mathrm{PASI} \leq 1$ or $\mathrm{BSA} \leq 3 \%$ in the skin-related component of the MDA contributed to the higher response rate relative to the PASI100 response. Thus, the PASI100 response is a more stringent endpoint. Proportions of responders are similar across MDA and ACR50+PASI100 individual components for HAQ and SJC. The high baseline TJC levels (mean TJC: IXE=19.1, ADA=21.3) as opposed to lower levels observed for baseline SJC (mean SJC: IXE=10.1, ADA=10.7) made MDATJC criterion ( $\leq 1)$ more difficult to achieve than the equivalent criterion of the ACR50+PASI100 endpoint.

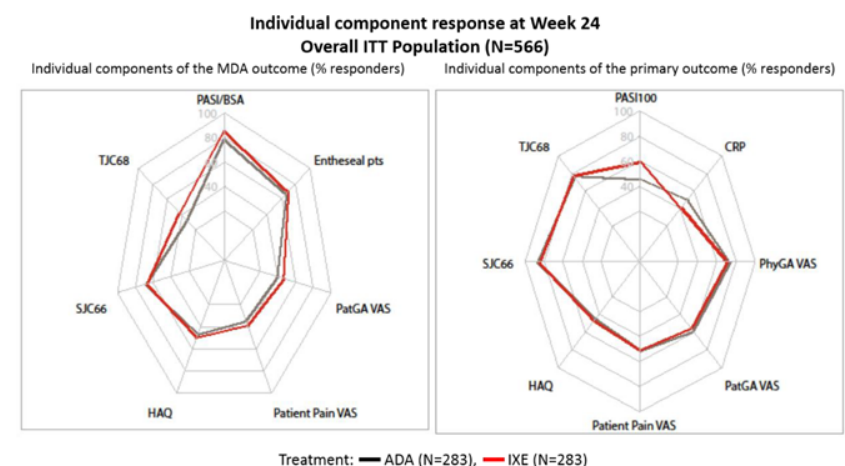

MDA response: $\quad$ Treatment: $-A D A(N=283),-1 X E(N=283)$

Patients need to fulfil 5 of the 7 criteria: TJC $\leq 1$, SIC $\leq 1$, PASI $\leq 1$ or BSA $\leq 3$, Patient pain visual analogue scale (VAS) score $\leq 15$, Patient global VAS score $\leq 20$, Health Assessment Questionnaire Disability Index (HAQ-DI) $\leq 0.5$, tender entheseal points (18) $\leq 1$ ACR50 response
Patients need to report $250 \%$ improvement in TJC and SSC and a $\geq 50 \%$ improvement in at least 3 of the following: Patient pain Patients need to report $250 \%$ improvement in TSC and SIC and a $250 \%$ improvement in at least 3 of the
VAS score, patient global VAS score, Physician global VAS score, HAQ-DI, high sensitivity CRP (hs-CRP).

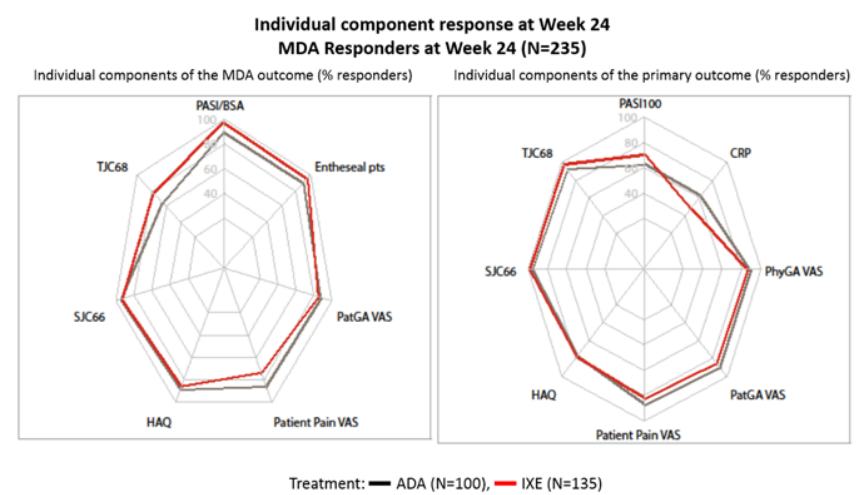

N.B Nine pts with active $P S O$ and $B S A 23 \%$ were assessed as $P A S \mathrm{~S}=0$ at baseline, a medical inconsistency that was resolved usin medical judgement. These patients were considered $P A S \mid 100$ responders if $P A S \mid=0$ and $B S A=0$ at post baseline visits

Conclusion: Despite the differences in criteria definitions, there are consistent response patterns in the individual components of the simultaneous ACR50+PASI100 and MDA endpoints in particular for the peripheral arthritis domain.

\section{References:}

[1] Smolen, Josef S et al. "Treating axial spondyloarthritis and peripheral spondyloarthritis, especially psoriatic arthritis, to target: 2017 update of recommendations by an international task force." Annals of the rheumatic diseases vol. 77,1 (2018): 3-17.

[2] Mease PJ The SPIRIT H2H study group, et al. "A head-to-head comparison of the efficacy and safety of ixekizumab and adalimumab in biological-naïve patients with active psoriatic arthritis: 24-week results of a randomised, open-label, blinded-assessor trial." Annals of the Rheumatic Diseases 2020;79:123-131.

Disclosure of Interests: Laura C Coates: None declared, Michael Nissen Grant/ research support from: Abbvie, Consultant of: Novartis, Lilly, Abbvie, Celgene and Pfizer, Speakers bureau: Novartis, Lilly, Abbvie, Celgene and Pfizer, Celine El Baou Consultant of: Eli Lilly and Company, Jane Zochling Employee of: Jannssen Cilag, Speakers bureau: Janssen Cilag, AbbVie, Novartis, UCB, BMS, Eli Lilly, Antonio Marchesoni Speakers bureau: Abbvie, Pfizer, UCB, Novartis, Celgene, Eli Lilly, Soyi Liu Leage Shareholder of: Eli Lilly and Company, Employee of: Eli Lilly and Company, Enrique Soriano Grant/research support from: AbbVie, Eli Lilly, GlaxoSmithKline, Novartis, Pfizer Inc, Sandoz, Consultant of: AbbVie, Eli Lilly, GlaxoSmithKline, Novartis, Pfizer Inc, Sandoz, Speakers bureau: AbbVie, Amber, Bristol-Myers Squibb, Eli Lilly, Novartis, Pfizer Inc, Roche, Valderilio F Azevedo Grant/research support from: Abbvie, Janssen, Bristol-Myers Squibb, Boehringer-Ingelheim, Lilly and Novartis, Consultant of: Lilly, Novartis, Janssen, Boehringer-Ingelheim, Amgen, Pfizer and Abbvie, Speakers bureau: Sandoz, Celltrion, Lilly, Novartis, Janssen, Boehringer-Ingelheim, Amgen, Pfizer and Abbvie, Klaus Machold Grant/research support from: AbbVie, MSD, UCB, Consultant of: Arsanis, Astro, Baxter, BMS, Celgene, Eli-Lilly, MSD, Pfizer, Roche, Novartis, Sandoz, Speakers bureau: MSD Pfizer, BMS, Janssen-Cilag, Sandoz, Novartis, Eli-Lilly, Christophe Sapin Shareholder of: Eli Lilly and Company, Employee of: Eli Lilly and Company DOI: 10.1136/annrheumdis-2020-eular.2830

\section{FRI0333 \\ ACHIEVEMENT OF VERY LOW DISEASE ACTIVITY AND REMISSION TREATMENT TARGETS IS ASSOCIATED WITH REDUCED RADIOGRAPHIC PROGRESSION IN PATIENTS WITH PSORIATIC ARTHRITIS TREATED WITH CERTOLIZUMAB PEGOL}

L. C. Coates ${ }^{1}$, J. F. Merola ${ }^{2}$, A. Kavanaugh ${ }^{3}$, P. J. Mease ${ }^{4}$, O. Davies ${ }^{5}$, O. IrvinSellers $^{5}$, T. Nurminen ${ }^{6}$, D. Van der Heijde ${ }^{7} .{ }^{1}$ Nuffield Orthopaedic Centre, Oxford, United Kingdom; ${ }^{2}$ Brigham and Women's Hospital, Harvard Medical School, Boston, United States of America; ${ }^{3}$ Division of Rheumatology, Allergy and Immunology, UC San Diego School of Medicine, La Jolla, United States of America; ${ }^{4}$ Swedish Medical Center and University of Washington, Seattle, United States of America; ${ }^{5}$ UCB Pharma, Slough, United Kingdom; ${ }^{6}$ UCB Pharma, Monheim am Rhein, Germany; ${ }^{7}$ Leiden University Medical Centre, Leiden, Netherlands

Background: Several disease activity measures and thresholds have been recommended as psoriatic arthritis (PsA) treatment targets, although consensus on the most appropriate assessment tool is lacking. ${ }^{1}$ Reports suggest low disease activity (LDA) and remission may be associated with minimal structural progression in PsA. ${ }^{2}$ 